correct the equinus when the quadriceps is gone, and retain plantar flexion of five to eight degrees when the quadriceps is present. Dr. Freiberg's remarks carry considerable weight. His results from tendon transplantations and those of many others which have come under my observation in Boston are not satisfactory. I have also looked up the results of arthrodesis in young children, and found that in 90 per cent. of the cases the old deformities recur or new ones appear. If tendon transplantation does not add to the stability of the foot and increase its function, it is not the best operation. When we take a tendon from one place and put it in another, we weaken the tendon and also weaken the side that it came from, and put it where it never can act to its full strength. I did not say that I used the Whitman operation in every case. If by tendon transplantation any of the surgeons here can obtain correction of the deformity, universally, increase function and secure stability, then it is certainly an operation for them on a par with astragalectomy. Dr. Jacobs asked about the average shortening that I obtain. Astragalectomy does not shorten the leg. The shortening in my cases was about $1 / 2$ inch to $11 / 2$ inch. In cases with the os calcis vertical the malleoli naturally lie nearer the ground following astragalectomy. The Galli operation has undoubtedly a prominent place in the treatment of infantile paralysis. Up to the present, however, my experience has not been such that I care to make any statements about it. I shall not do so until I have formed definite conclusions. Dr. Ryerson says that the pendulum has started to swing too strongly in the direction of astragalectomy. Dr. Whitman has tried to impress the value of astragalectomy as compared with tendon transplantation before, and failed. With regard to this operation, it is on a similar plane with all the other surgical procedures that he has advanced. Nothing has been found as a substitute for them. Dr. Campbell spoke of inversion. I had that happen in three cases. These inversions are very objectionable deformities. I was able to correct them by placing the fibula further forward, holding it there by means of the Galli operation; suturing the peroneal tendons into the fibula. These patients are all right now.

\section{INTESTINAL OBSTRUCTION DUE TO ASCARIS LUMBRICOIDES}

\section{REPORT OF A CASE \\ J. MAXIME PERRET, M.D., AND \\ H. THEODORE SIMON, M.D. NEW ORLEANS}

In the latter half of the nineteenth century, opinion was divided as to the possibility of Ascaris lumbricoides being the etiologic factor in intestinal obstruction; thus, Leichenstern and Treves opposed this view, while Trousseau, Bretonnear and Stutz ${ }^{1}$ upheld it, each having been among the first to report cases.

Bordoroni and Stepp in 1887 reported two cases, both of which were confirmed postmortem.

Simon, ${ }^{2}$ in 1892, while holding a necropsy in a case of intestinal obstruction, found the cause to be a mass of roundworms.

Botoff, ${ }^{8}$ in 1897 , reported a case of obstruction, perforation and peritonitis, in which the postmortem revealed the presence of 500 roundworms.

1. Huber, J. C. Trousseau, Bretonneau and Stutz, in Twentieth Century Practice of Medicine.

2. Simon: Rev. méd. de l'est., 1892, p. 228.

3. Botoff: Jour. d. clin. et thérap, inf., 1897, No. 10.
In 1899, Taylor found sixty-six worms in a case of intestinal obstruction.

Zotoff ${ }^{5}$ reports a case of Mosler and Peiper of a 3 year old girl who died of peritonitis with two perforations in the ileum, $171 / 2$ inches from the cecum; through one of these openings twenty-five round worms projected; the ileum between this point and the cecum, ascending colon and transverse colon were completely filled with roundworms, numbering 500 in all.

Van Meter $^{8}$ reports a case of a child aged 5 years, having a sausage-like mass above and to the left of McBurney's point, in which operation revealed in the lower part of the ileum a coil of roundworms causing complete obstruction; the author says that there were almost enough parasites "to fill a wash basin"; the patient recovered.

A case, reported by Venning, ${ }^{7}$ of a $21 / 2$ year old boy who was operated on and died, was diagnosed before surgical intervention by palpation of the intestinal masses through the abdominal wall; 273 worms were removed, the site of obstruction being the jejunum, ileum and cecum.

Vickery ${ }^{8}$ was called to see a pregnant woman with symptoms of intestinal obstruction and a history of vomiting several roundworms; on being given a dose of sanotin, followed by castor oil, she. vomited twelve roundworms. The symp toms of obstruction disap. peared, and excepting for the sudden termination of gestation, she made an uneventful recovery.

Takaki ${ }^{0}$ reports a case of acute obstruction in a 3 year old child with com plete recovery following the vomiting of 115 roundworms.

Having consulted the records of Charity Hospital in the ten years from 1906 to 1916 , we find 112 cases of intestinal obstruction, in ninety adults and twenty two children, and of these, there is but one case in which the roundworm is the etiologic factor. The patient was a young negro girl who was operated on for obstruction. A portion of the intestine was filled with a mass of worms. The condition necessitated a resection of the intestine, and a Murphy button was used ; shortly afterward, after some apparent improvement, the child died, and necropsy revealed the presence of a roundworm in the lumen of the button, which it occluded.

\section{REPORT OF CASE}

History.-M. M., white girl, aged 8 , was admitted to 2 surgical ward on the evening of March 14,1916, having bee referred by an attending physician for surgical intervention of what he rightly diagnosed acute intestinal obstruction. The family history was of interest, as the patient's five sisters and brothers had passed roundworms on many occa ${ }^{\circ}$ sions. The past history was negative except that the child had frequently passed roundworms since the age of 2 .

Five days prior to admission, the child was suddenly taken ill with a pain in the right lower abdominal quadrant, and

4. Taylor: Am. Jour. Obst., 1899, p. 808.

5. Zotoff, in Nothnagel: Encyclopedia of Practical Medicine.

6. Van Meter, B. F.: Intestinal Obstruction Due to Roundworm" Surg., Gynec. and Obst., $1909, \mathbf{8}, 409$.

7."Venning, R. E.: Infestinal Obstruction from Ascarides Lumbri coides, Tue Journat, A. M. A., June 18, 1910, p. 2041. coides, Tick JouRNAL, A. M. A., June 18,1910, p. 2041 . Coil of Worms
Brit. Med. Jour., $1913,2,1534$.

9. Takaki, Y.: Sei-I.Kwai, June, 1915. 
slight elevation of temperature. On the second day she began to vomit, and this continued up to the time of admisof castore vomitus consisted of a clear watery fluid. A dose stool or oil was given the second day and only a very small under passed, with no more bowel movements until she came under our observation.

TEMPERATURE, PULSE AND RESPIRATION

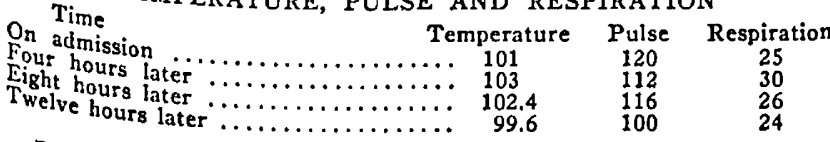

Physical Examination.-The child was poorly developed and nourished. The skin was of a slight sallow tint. The slands in neck and groin were enlarged. The eyes were badly, with dark hollows under the orbits. The teeth were nose kept. The tongue was dry and coated. The throat, were, ears and heart were negative. Coarse mucous râles orly heard over the lower half of the right lung, both anteripanitic; posteriorly. The abdomen was distended and tymin the regice was no rigidity. In the left lower abdomen, was region of the sigmoid, a mass the size of a large lemon was palpated. The viscera tremities palpable. The exnegative and reflexes were

Laboratory Reports: There was a total white blood count of 16,800 per cubic millimeter. The differential white 21 count revealed: lymphocytes, 21 per cent.; endothelial trukocytes, 3 per cent.; neutrophils, 67.5 per cent.; Exinophils, 8.5 per cent. Examination of the urine revealed: albumin and sugar, negative; indican, strongly positive; microscopically, a After lecytes.

After the examination a purgative enema was given fecal returned colored with a matter and containing a mass of approximately interwoundworms, coiled and of a second child's closed fist. A returned enema was given and fecal hed highly colored with was matter. The distention for relieved, and excepting first a rise in temperature the conditiont hours, the patient's twelve hours improd, and in

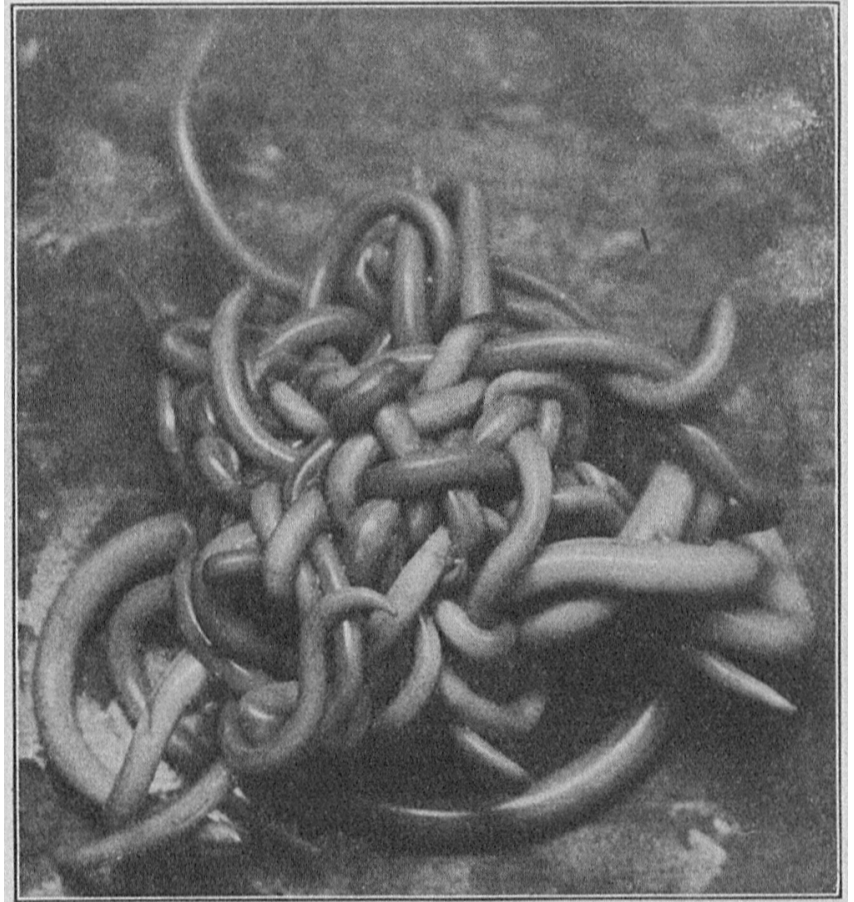

Mass of approximately forty Ascarides lumbricoides, $\times 1 \frac{1}{3}$, expelled in a case of acute intestinal obstruction.
MECIANICAL PROBLEMS OF BRONCHOSCOPIC AND ESOPHAGOSCOPIC FOREIGN BODY EXTRACTION *

CHEVALIER JACKSON, M.D. PITTSBURGH

In dealing endoscopically with foreign bodies lodged in the larynx, trachea, bronchi or esophagus, it is fundamentally necessary to remember that the problem is not simply to remove the foreign body but to remove it with little or no risk to the patient. It is always necessary to remember that a patient is far safer with a foreign body in his air or food passages than he would be if the intruder were ruthlessly torn out at all hazards. Ruthless withdrawal is comparable to the act of the ignorant farmer who hitches a team of horses to the malpresented calf. Only in the rarest instances is immediate removal necessary, and it is far better to desist at once if at the first bronchoscopy it is found that special instruments will need to be devised to remove the intruder. On the other hand, it is never wise to make the first bronchoscopy without having prepared beforehand everything that can possibly be needed, so far ats it is possible to foresee from a study of the roentgenogram, history, symptoms and physical signs.

The experience resulting from the encounter with foreign bodies of almost all conce ivable shapes and substances has resulted in an armamentarium $w$ hich probably can deal with all kinds of foreign bodies. When the bronchoscopist first catches sight of a foreign hody for which he has been searching, the temptation to seize it by whatever part is visible and to pull on it with all the strength of which his forceps are capable is very great; and one might say that the temptation is greater directly as the duration of the search.

Yielding to this temptation has been the cause of more mortality in foreign-body bronchoscopy and esophagoscopy than any other single factor. Moreover, hasty, injudicious traction of this kind will very often not only fail to remove the foreign body but will so complicate the situation as to render subsequent removal exceedingly difficult. In other words, the mechanical problem is converted from a very simple into a very complicated one, just as pulling on a tangled mass of string will render subsequent disentanglement difficult or impossible. Therefore, it may be stated that there are three reasons why the study of the mechanical problems of foreign-body extraction constitute the most important study in foreign-body endoscopy.

* Rend before the Section on Laryngology, Otology and Rhinology at the Sixty.Seventh Annual Session of the American Medical Associa. tion, Detroit, June, 1916. 